\title{
TWENTY YEAR DEVELOPMENT OF OCCUPATIONAL DISEASES IN THE CZECH REPUBLIC: MEDICAL AND GEOGRAPHICAL ASPECTS
}

\author{
Jan Jarolímek ${ }^{1,2}$, Pavel Urban ${ }^{3,4}$ \\ ${ }^{1}$ Department of Social Geography and Regional Development, Faculty of Science, Charles University, Prague, Czech Republic \\ 2Public Health Authority of Central Bohemia Region, Prague, Czech Republic \\ ${ }^{3}$ Department of Industrial Hygiene and Occupational Health, National Institute of Public Health, Prague, Czech Republic \\ ${ }^{4}$ Department of Occupational Medicine, 1st Faculty of Medicine, Charles University, Prague, Czech Republic
}

\section{SUMMARY}

The study analysed occupational diseases in the Czech Republic from the viewpoint of occupational medicine and medical geography. It used a dataset consisting of 32,646 cases of occupational diseases reported during the period of 1994-2013. The descriptive part of the study analysed occupational diseases according to their spatial distribution, occurrence in different branches of economic activities, employees' gender, and according to chapters of the List of occupational diseases. The incidence of occupational diseases showed an overall decreasing trend, which can be related to several factors - transformation of the national economy (shift from heavy industry to manufacturing industry and services), an improvement in access to occupational healthcare services, increased responsibility of employers for safe working conditions, but also a concealment of health problems by employees for fear of losing job. An exception to the decreasing trend is the automotive industry, in which the upward trend in occupational diseases occurrence was noted. The analytical part of the study focused on the relation between unemployment and occupational diseases incidence rates in different regions of the Czech Republic. In most regions, a statistically significant inverse association was shown between the rate of unemployment and occupational disease incidence. The situation is described in more detail for the Moravia-Silesia and Ústí nad Labem Regions and the Capital City of Prague, wherein a statistically significant inverse association was shown between the rate of unemployment and occupational disease incidence. The theory of marginal utility can explain the phenomenon. To certain degree of health problems, employees tend to prefer employment stability, especially if the unemployment is on rise in their region. On the other hand, if losing their job, they often try to claim benefits connected with occupational diseases.

Key words: occupational diseases, medical geography, geography of health, ecological correlational study, unemployment, risk factors

Address for correspondence: J. Jarolímek, Charles University in Prague, Faculty of Science, Department of Social Geography and Regional Development, Albertov 6, 12800 Prague, Czech Republic. E-mail: jan.jarolimek@natur.cuni.cz

\section{INTRODUCTION}

Geography encompasses a scientific field called medical geography, which is defined by Meade and Emch (1) as an interdiscipline with overlaps between physical geography and social and medical sciences. It puts together biological, environmental and social aspects with an emphasis on relations of people, places, environment and time on the one hand and health issues on the other. Medical geography uses quantitative and qualitative methods, geographical information systems (GIS) and depicts spatial connections with map projection (2). A related term is health geography, which is applied in the area of public health and focuses more on the social aspect of health $(3,4)$.

Occupational diseases (OD) represent one of the most serious concequences of exposure to hazardous risk factors connected with occupation from the medical, social and economic point of view. Their occurrence is characterised by regional and industrial sector differences and demonstrates considerable time and space dependent dynamic. In 2013, we performed a pilot study, which analysed OD in automotive industry in the Central Bohemia Region during 2006-2011 $(5,6)$. Results of the study pointed out the possible influence of socioeconomic factors such as employment stability and salary rates on the occurrence of OD.

The principle objective of this subsequent extended study is the analysis of spatial and time dependent trends of OD occurrence in the whole Czech Republic during the period of 20 years. We also attempted to answer the question, whether there is a relation between OD occurrence and unemployment rate, as it was suggested by our previous study.

\section{MATERIALS AND METHODS}

The period 1994-2013 was chosen for the study. Data on OD cases were retreived from The National Registry of Occupational Diseases (7), and were analysed according to employees' gender, age, List of OD, occupation risk category, and branch of economic activity. Up to 2007, economic activities were classified in accordance with the national industrial Branch Classification of Economic Activities, which has been substituted by classification CZ-NACE since the 1st January 2008 in compliance with EP and EC regulation No 1893/2006 (8). In order to analyse and compare 
data from both periods, we reclassified data from 1994-2007 according to CZ-NACE.

Data on the average unemployment rate in regions of the Czech Republic were obtained from the Director General Labour Office of the Czech Republic. In 2013, the Czech Republic stopped using the parameter of average unemployment rate and instead started using the weight of economically active population (EAP) aged 15-64 years in total population of the same age. The calculation of the unemployment rate in 2013, which would be in line with the previous methodology, was not possible. Therefore, we did not include data on unemployment in 2013 in our analysis.

\section{Data Analysis}

To analyse relation between two quantitative parameters, the linear regression and calculation of Pearson correlation coefficient were used. The level of statistical significance was set at $\mathrm{p}<0.05$. Calculations were performed with Microsoft Excel (version 2013) using functions for regression and correlation analysis (CORREL and PEARSON). Control parallel calculations were performed using online statistical software available on the website http:// statpages.org/.

The occurrence of OD was expressed in absolute counts and also as a relative indicator - the incidence rate, calculated as the number of cases per 10,000 economically active population.

Map data were processed using ArcMap (version 10.2.1, ESRI); data were plotted on vector digital geographic database ArcCR 500 at 1:500,000 scale (version 3.1) using the database of Administrative Division in the Czech Republic - shapefile Regions of CZ. The text part of the work was processed with Microsoft Word (version 2013) and charts were created with the version of Microsoft Excel stated above.

\section{RESULTS}

The analysed dataset consisted of 32,646 cases of OD, which were reported in the Czech Republic during the selected period. Most of them were caused by physical factors, i.e. chapter II of the List of occupational diseases (41.2\%), followed by chapter III - OD affecting respiratory tract, lungs, parietal pleura, and peritoneum (19.9\%), chapter IV - OD of skin (19.2\%), and chapter $\mathrm{V}$ - infectious and parasitic OD (17.5\%).

Fig. 1 represents the occurrence of occupational diseases in the Czech Republic in 2004-2013 in absolute counts. The decreasing trend in their occurrence is evident in a long-term horizon.

Figures 2 and 3 depict OD incidence rate in each region of the Czech Republic in the first and last year of the studied period, i.e. in 1994 and 2013. The same intervals of OD incidence rates were used for the sake of clarity in both cartograms (see respective legends). As can be seen, the OD incidence rate has a decreasing trend with 4.1 cases per 10,000 EAP in 1995 and 1.4 cases per 10,000 EAP in 2013, even though the overall proportion of economically active population (that is inhabitants between 15 and 64 years) used in calculation did not significantly change. In 1995, EAP registered in the Czech Republic was about 7,056 thousands, while in 2013 it consisted of 7,100 thousands.

The manufacturing industry (CZ NACE section C) is among the industrial sectors with the highest rate of OD occurrence.

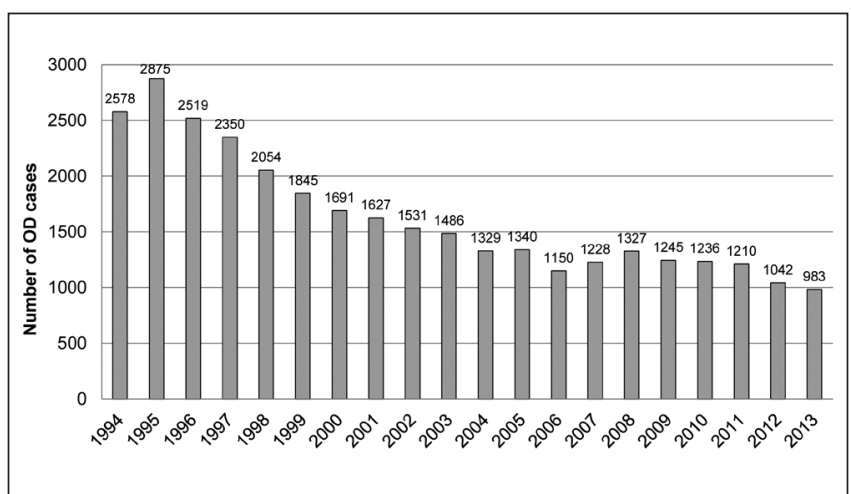

Fig. 1. OD cases in the Czech Republic in 1994-2013.

It represented almost $46 \%$ of all 36,646 recognised cases; followed by mining industry (CZ NACE section B) with almost $22 \%$, and human health and social work activities (CZ NACE section Q) - $15 \%$.

While the OD incidence in manufacturing industry has demonstrated a long-term decreasing trend, a significant deviation was detected in the case of automotive industry (CZ NACE section C29), wherein the OD incidence rate has shown a significant increase (Fig. 4). For the sake of clarity, only five branches of manufacturing industry with the highest OD incidence rates are

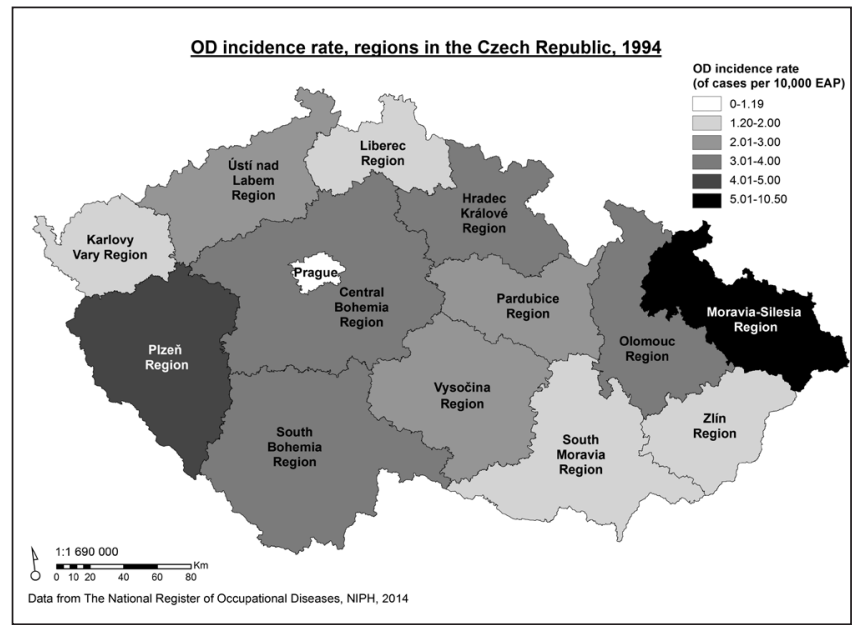

Fig. 2. OD incidence rate, regions in the Czech Republic, 1994.

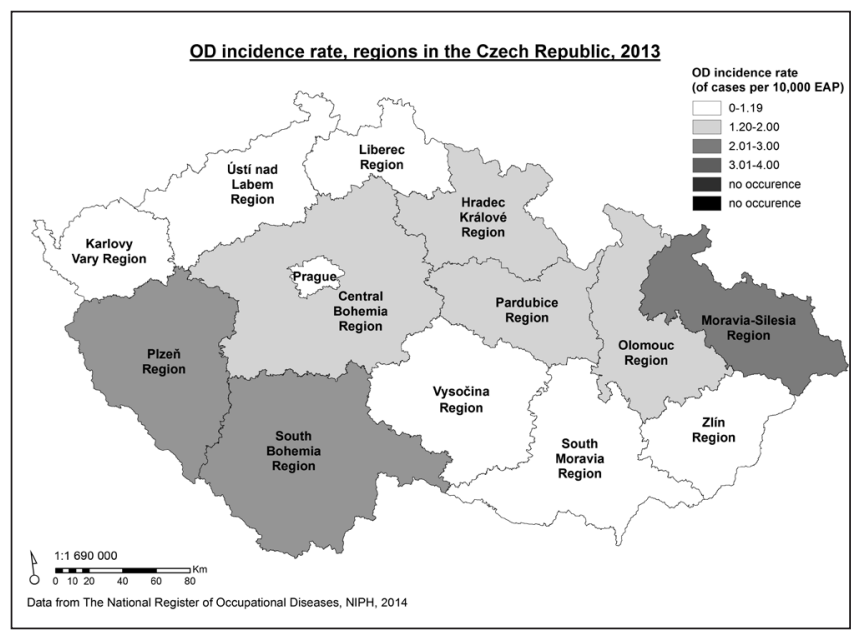

Fig. 3. OD incidence rate, regions in the Czech Republic, 2013. 
depicted. OD occurrence is expressed as an Incidence Rate Ratio with 1994 as a reference year.

The proportion of OD in CZ-NACE C29 (automotive industry) in total numbers of OD cases has been continuously rising since 2003 and has been gaining in branches with traditionally highest numbers of OD cases - i.e. health services and mining. While in 2007 the automotive industry ranked seventh, it rose to the 2nd position in 2013 .

Concerning gender differences in OD occurrence, women constituted $39 \%$ and men $61 \%$ of 32,646 of reported cases. However, this ratio demonstrated considerable regional differences. Men dominated in Moravia-Silesia Region ( $81 \%$ of all OD cases), Central Bohemia Region (61\%), and Plzeň Region (57\%). The regions where women prevailed were represented by Liberec Region (66\%), Ústí nad Labem Region (65\%), and Karlovy Vary Region (60\%). We assume that these gender differences are related mostly to the structure of economic activities in respective regions.

Potential association between the unemployment rate and the OD incidence was tested by correlation and regression analysis. Fig. 5 represents results of regression analysis performed for all regions in the Czech Republic from 1994-2012. The regions are arranged in descending order according to the absolute value of Pearson correlation coefficient.

Five regions demonstrated a highly significant $(\mathrm{p}<0.001)$ inversion relationship between the unemployment rate and the OD incidence (Moravia-Silesia, Ústí nad Labem, Plzeň, South Moravia, and Hradec Králové Regions). Zlín Region, the Capital City of Prague, Vysočina and Pardubice Regions showed significant association $(\mathrm{p}<0.01)$. Results for Liberec and Karlovy Vary Regions bordered on a statistical significance $(\mathrm{p}<0.05)$. Associations of those two parameters for South Bohemia, Central Bohemia and Olomouc Regions did not reach statistical significance.

Fig. 6 depicts a relationship between the unemployment rate and the OD incidence per 10,000 EAP in 1994-2012 nationwide. There was a steep increase in unemployment in the Czech Republic since 1997, which culminated in 2004 (approx. 300\% increase compared to reference year 1994), followed by moderate decline untill 2008 (approx. 160\% of its value in 1994) with a subsequent increase until reaching its present relatively stable value (approx. 260\%). Meanwhile the OD incidence demonstrated

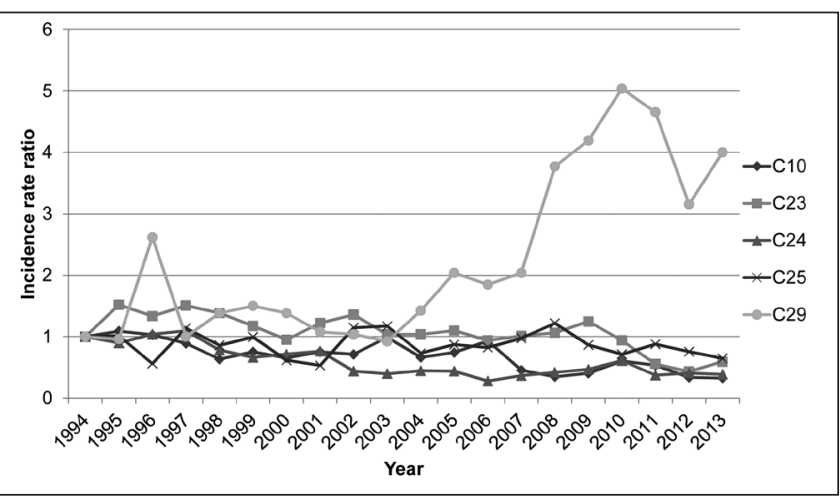

Fig. 4. $O D$ incidence in the some branches of manufacturing industry in the Czech Republic in 1994-2013.

C10 - Manufacture of food products, C23 - Manufacture of other non-metallic mineral products, C24 - Manafacture of basic metals, C25 - Manufacture of fabricated metal products, except machinery and equipment, and C29 - Manufacture of motor vehicles, trailers and semi-trailers (also termed automotive industry).

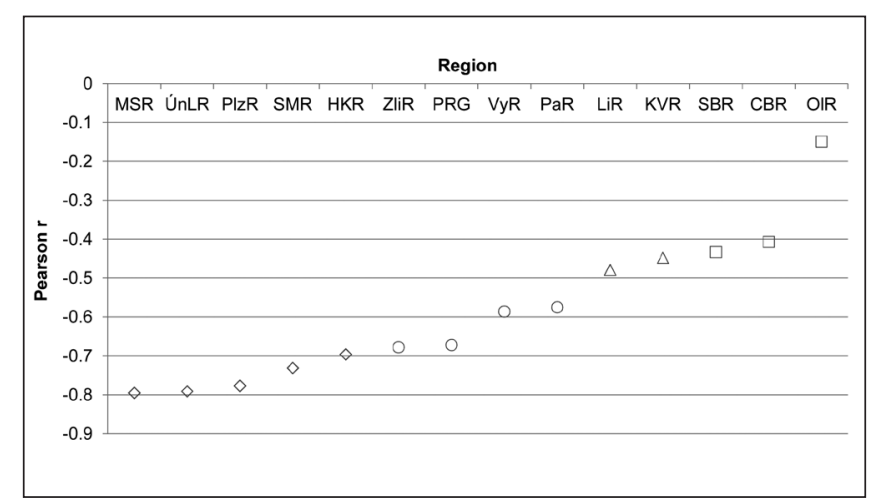

Fig. 5. Correlation between unemployment rate and $O D$ incidence for individual regions.

Diamonds represent statistical significance $p<0.001$, circles $p<0.01$, triangles $\mathrm{p}<0.05$, and squares N.S.

MSR (Moravia-Silesia), ÚnLR (Ústí nad Labem), PIzR (PIzeň), SMR (South Moravia), HKR (Hradec Králové), ZliR (Zlín) PRG (Prague), VyR (Vysočina), PaR (Pardubice), LiR (Liberec), KVR (Karlovy Vary), SBR (South Bohemia), CBR (Central Bohemia), OIR (Olomouc Region).

a monotonous decrease untill 2012 , when it reached $40 \%$ of its value in reference year 1994 (Fig. 6).

To illustrate this relationship on regional level, three regions were selected: Moravia-Silesia and Ústí nad Labem Regions with highly significant inverse relationship. The Capital City of Prague was chosen as the economically most developed region of the Czech Republic in terms of gross domestic product (GDP) with low unemployment rate.

From the analysis of this relationship in the three selected regions (Fig. 7-10), it can be implied that the development of unemployment in the structurally most affected and economically most deeply transforming Moravia-Silesia Region is following a trajectory similar to a national development. However, development of OD incidence is, contrary to nationwide situation, not monotonous, but mirrors the unemployment curve, i.e. as unemployment increased (1997-2005), the OD incidence was decreasing, while during decrease in unemployment (2006-2010), the OD incidence was slightly rising. At the end of monitored period (after 2009), both parameters stabilised above the national level.

The Ústí nad Labem Region also has the unemployment rate above the national average occasionally surpassing even the unemployment rate in Moravia-Silesia Region and it altogether

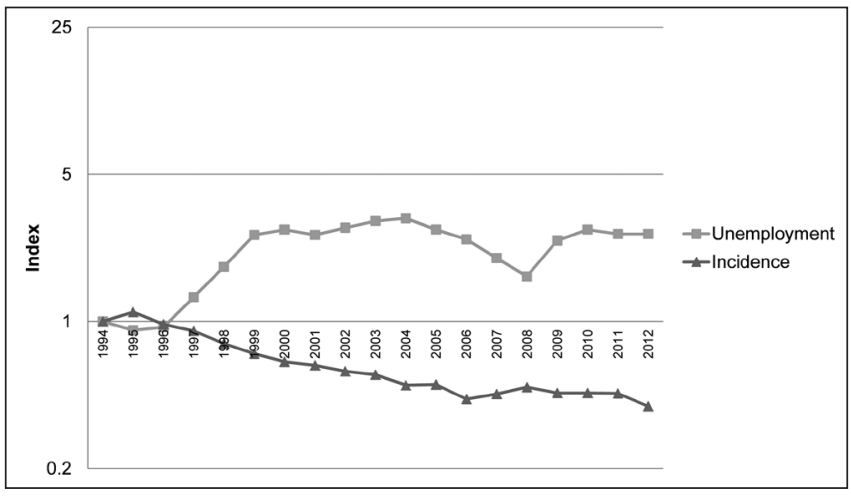

Fig. 6. Unemployment and OD incidence in the Czech Republic in 1994-2012.

The ordinate is in logarithmic scale and represents index values, whose base is the value in reference year 1994. 
demonstrates similar development of this parameter. After 2009 it remains constantly above the level of Moravia-Silesia Region. The development of both analysed parameters displays a sign of mirror imaging.

The situation in the Capital City of Prague is distinctly different in terms of low values of both compared parameters. This may be related to the specific structure of occupations with a higher proportion of services, including health services. The development of unemployment demonstrated tendency analogous to the

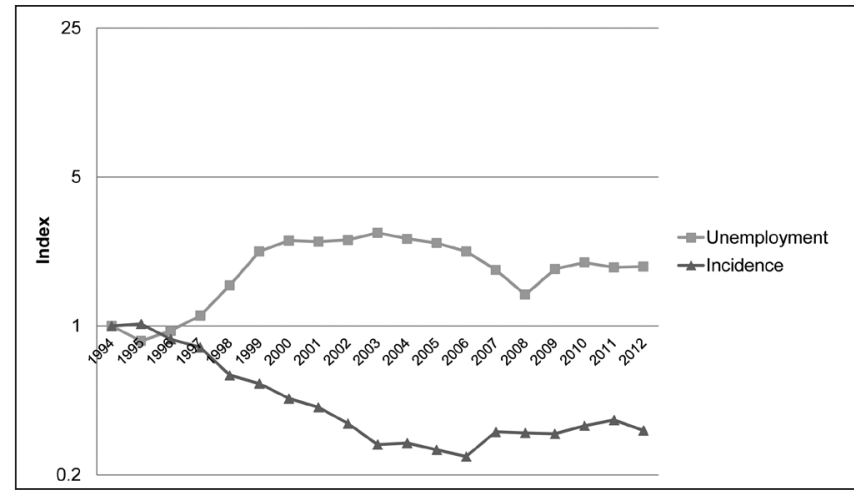

Fig. 7. Unemployment and $O D$ incidence in Moravia-Silesia Region in 1994-2012.

The ordinate is in logarithmic scale and represents index values, whose base is the value in reference year 1994.

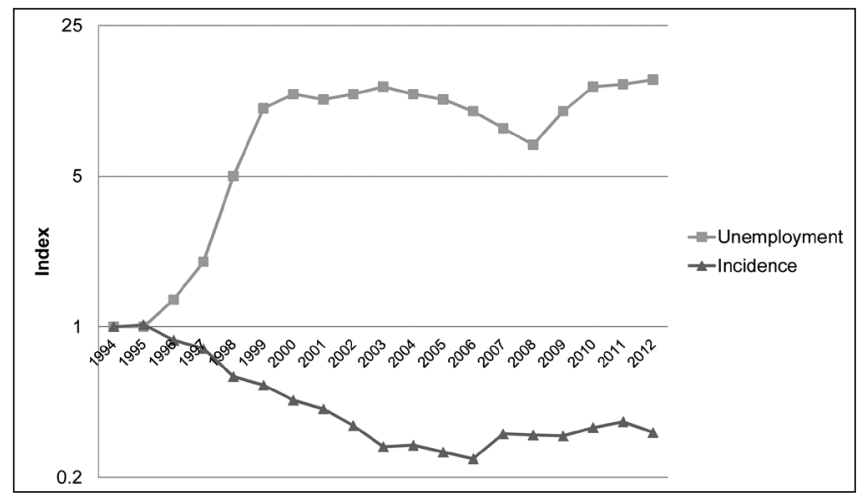

Fig. 8. Unemployment and $O D$ incidence in Ústí nad Labem Region in 1994-2012.

The ordinate is in logarithmic scale and represents index values, whose base is the value in reference year 1994.

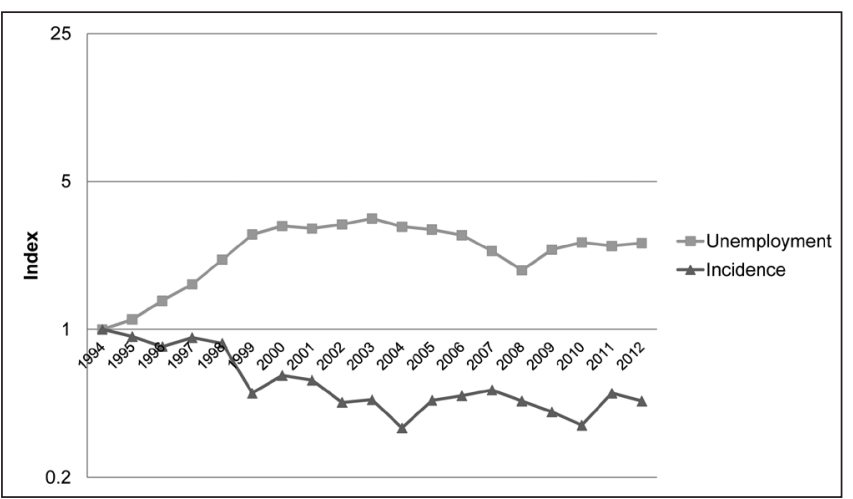

Fig. 9. Unemployment and OD incidence in the Capital City of Prague in 1994-2012.

The ordinate is in logarithmic scale and represents index values, whose base is the value in reference year 1994.

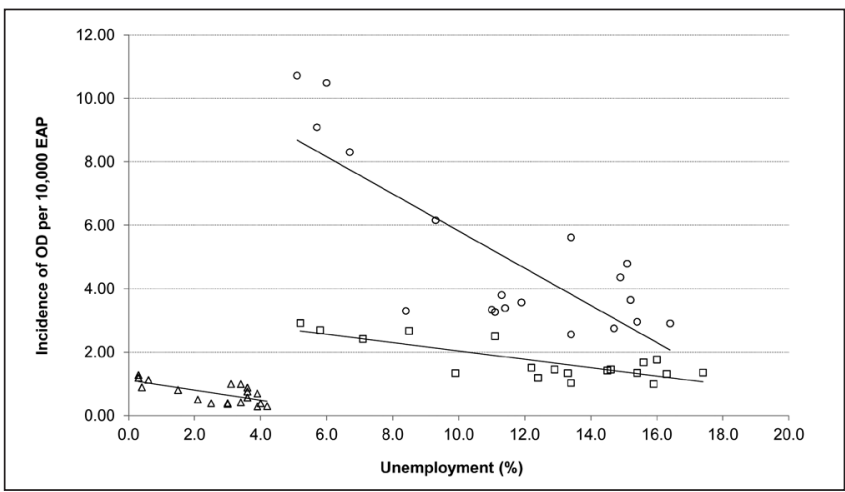

Fig. 10. Relationship between the unemployment rate and $O D$ incidence in the Moravia-Silesia and Ústí nad Labem Regions and in the Capital City of Prague.

Triangle is the Capital City of Prague, square is Ústí nad Labem Region and circle is Moravia-Silesia Region.

national trend and the OD incidence reached negligible values within $1 \%$. It can be assumed that these relatively low values in comparison with Moravia-Silesia or Ústí nad Labem Region are related not only to different structure of the economy, but also to tendency to trivialise or deliberately neglect health problems for fear of losing earnings, which in Prague are above national average.The mirror course of both curves is apparent here as well.

\section{DISCUSSION}

In the descriptive part of our study, we observed a decreasing trend of OD occurrence in all regions of the Czech Republic in the period from 1994-2013 in terms of both absolute numbers of reported cases and their relative incidence. Contrary to the overall trend, a significant deviation was observed in the branch of economic activity CZ-NACE C29 (automotive industry), which demonstrated an increase in the OD occurrence. This became apparent in 2004-2005 and culminated in 2010, when the Incidence Rate Ratio for this branch (reference year 1994) reached a value of 5.04. This is in agreement with a press release of the Ministry of Health of the Czech Republic from the 1st August, 2013 (9), which stated that the most occurring occupational diseases in 2013 were peripheral nerves disorders caused by overstraining of limbs and affecting most often assembly workers in automotive industry. The second most numerous group of OD in 2013 were peripheral nerves disorders caused by vibration mostly in branches, which involve handling of vibrating machines (construction, mining and metalworking industry), and disorders of tendons, tendon sheaths, ligaments and joints, which have been most often diagnosed in assembly workers.

There are certainly multiple reasons for the observed decrease in OD occurrence trend. Besides other things, it can be presumed that higher responsibility of employers for safer working condition has played an important role. Access to high-quality occupational health services has improved recently as well. According to the report on activities of public health authorities in the field of occupational health and safety (10), $42.6 \%$ of employees were not covered with occupational health services in 2007, and the number dropped to $33.1 \%$ in 2012 . Counts of workers exposed to occupational risk factors had also demonstrated a downward trend. According to the Registry of Job Categorisation (11), the 
highest risk category, i.e. category 4 , represented $4.13 \%$ of the total number of all high-risk occupations in 2005, while the number dropped to $3.12 \%$ in 2013. In absolute counts, the decrease was from 17,117 workers in the highest risk occupations in 2005 to 14,748 in 2013 . Another factor possibly associated with this decreasing trend of OD occurrence is an effective surveillance of workplaces by regional public health authorities.

Results of our previous pilot study $(5,6)$ suggested the role of socio-economic factors, such as the unemployment rate, in the occurrence of OD. Therefore, we further focused on relation between the unemployment rate and the OD occurrence in the analytic part of our work. We hypothesised that a higher unemployment rate would be correlated with a lower OD occurrence and our analysis supported the assumption.

Our work had design of an ecologic study, whose inherent limitation is a principal impossibility to prove a causal relationship. We are fully aware of the fact that statistical association between an unemployment rate and OD incidence, no matter how significant it is, does not necessarily imply a causal relationship between both phenomena. Nevertheless, we believe that our results are compatible with this possibility, or even corroborate it with respect to the mirror inversion course of time development of both phenomena.

The theory of marginal utility may offer an explication of the inverse association between unemployment and OD incidence. According to this theory, employees tend to prefer - to a certain degree of health problems - stability of an employment and income certainty (especially in regions with the above-average salary) to the threat of unemployment or transfer to other, less remunerative, albeit safer job. At the time of increasing unemployment, people esteem their job and endeavour not to lose it. They tend to prefer working with increased health risk and/or health problems to living on unemployment benefits with a small chance of finding a new job. That can be reason why employees deliberately hide their health problems from their general practitioner even during regular health checks.

Opposite situation happens, when company plans to dismiss employees, e.g. due to reorganisation. Concerned employees change their strategy and try to improve their situation by claiming OD benefits. The employees start to disclose their health problems at the moment, when they are made redundant.

Because economic and social environment and regional mentality (ways of thinking, chosen strategies, and value orientation) demonstrate distinct differences between regions in the Czech Republic, we performed an analysis of relation between the unemployment rate and the OD occurrence in different regions. It is an example of a subselection from the whole dataset. The statistical theory describes Simpson paradox for this context, or in other words the problem of spatial non-stationarity of regression relationships (12-14). There is a possibility of reversing the direction of dependency by effect of another variable when compared with the zero-order relationship (relationship observed with basic dataset). This phenomenon must be always considered whenever data are merged together; as in our case the aggregated data for the whole Czech Republic (15).

The reason for spatial non-stationarity of regression and correlation relationships is their real nature. Spatial differences can be a result of different attitudes, preferences, and reactions to the same stimulus. Administrative and political environment (i.e. different contextual factors) also play role. The idea of space dependent changes in behaviour and strategies of individuals is in line with postmodern approaches in geography, which put emphasis on the importance of place and local conditions in attempts at understanding of certain behavioural patterns $(12,16)$. Therefore, an identification of local and regional difference is crucial for a strategy of further research and for potential subsequent pragmatic measures.

One of the limitations of our study is the aggregate character of our data. They consist of average values, proportional and intensity indicators related to total population of a given region (administrative districts of municipalities with extended powers, districts, regions). This approach minimises a danger of selection and systematic biases of obtained results in most mass phenomena, but on the other hand these aggregate data say nothing about individuals, and little or nothing about specific groups of people defined by demographic and social categories (age, gender, education, economic activity, etc.), because deviations and differences within studied region cancel each other out in the aggregate parameters. This puts a principal limit on studying a relationship between basic socio-economic characteristics of people and their behaviour, preferences, value orientation, life or work strategies, and how this behaviour (and health condition) can be affected by a "quality" of their environment (in the meaning of ecological and social quality of their inhabited living space, wherein people spent majority of their everyday life). Therefore, presented results must be perceived only as a basis for a broader, i.e. contextual comparison of the situation in studied regions. Even though aggregate data cannot serve for an assessment of the role of confounding factors modifying OD occurrence, such as commuting, labour force fluctuation, intensity of employment in a given region, etc., they can be used for inferring possible relation to local specific culture in terms of social microclimate $(5,6)$.

Another limitation of our study lies in changes in unemployment calculation methodology and code lists of branches of economic activities during studied period. Even though these changes were taken into account and reflected in analysis, the reliability of data comparison during studied 20 year period might be questioned.

An international comparison of OD occurrence is highly problematic. No unified methodology, which would prescribe a standardised way of OD registration and their subsequent comparison, exists in the EU countries. Although a possibility of harmonisation of OD registering in EU within the EODS system was tested, the results showed that international comparison is rather limited and because several countries were not able to fulfil all the requirements of EODS due to technical or legal reasons, the European Commission has temporarily suspended this project.

\section{CONCLUSION}

In conclusion, it is important to emphasise the fact that ODs are in principle preventable. The proper occupational healthcare services play a key role in health protection of employees. Pre-employment medical examination is important especially in cases of high risk job positions, as it can reveal applicant's predispositions to certain occupational diseases and thus prevent an employment of the person on unsuitable position. Equally 
important are periodic medical examinations of employees. Their main purpose is to detect early potential deviations from normal health status, which represent contraindication for employee to continue working on the job position.

\section{Acknowledgements}

The authors thank to associate professor Dagmar Dzúrová and dr. Eva Heřmanová for advice and valuable comments, to Ondřej Košata and Marie Bílková for supplying several data used in our study, to dr. Bohumír Procházka for statistical consultations, and to Luke McFarline for linguistic assistance.

\section{Conflict of Interests}

None declared

\section{REFERENCES}

1. Meade MS, Emch M. Medical geography. New York: Guilford Press; 2010.

2. Meade MS, Earickson RJ. Medical geography. New York: Guilford Press; 2005.

3. Gatrell AC. Geographies of health: an introduction. Oxford: WileyBlackwell; 2001.

4. Anthamatten P, Hazen H. An introduction to the geography of health. New York: Routledge; 2011.

5. Jarolímek J. Occupational diseases in the automotive industry in terms of Central Bohemia Region [thesis]. Brno: Masaryk University in Brno, Faculty of Science, Department of Geography. (In Czech.)

6. Jarolímek J. Occupational diseases in the automotive industry in the Central Bohemia Region. Prakt Lek. 2013;93(3):100-4. (In Czech.)

7. National Institute f Public Health. National Registry of Occupational Diseases [Internet]. Prague: National Institute of Public Health; 2014 [updated 2014 Apr 20; cited 2014 Jul 17]. Available from: http://www. szu.cz/publikace/data/nemoci-z-povolani. (In Czech.)
8. Czech Statistical Office. Classification of economic activities (CZNACE) [Internet]. Prague: Czech Statistical Office [updated 2009; cited 2014 Jan 24]. Available from: http://apl.czso.cz/iSMS/en/klasstru. jsp?kodcis $=80004$. (In Czech.)

9. Ministry of Health of the Czech Republic. Miners suffer from occupational diseases most [Internet]. Prague: Ministry of Health of the Czech Republic; 2013 [updated 2013; cited 2014 May 15]. Available from: http://www.mzcr.cz/dokumenty/nemocemi-z-povolani-trpi-nejvicehornici-_8113_2778_1.html. (In Czech.)

10. Ministry of Health of the Czech Republic. Report on activities of public health authorities in the field of occupational health [Internet]. Prague: Ministry of Health of the Czech Republic [updated 2012; cited 2014 Jul 28]. Available from: http://www.mzcr.cz/Verejne/obsah/zprava-ocinnosti-oovz 2634 5.html. (In Czech.)

11. Registry of job categorisation [Internet]. Prague: KSRZIS [updated 2014 Apr 24; cited 2014 Jan 24]. Available from: http://www.ksrzis.cz/ dokumenty/registr-kategorizace-praci-kapr_41_114_1.html. (In Czech.)

12. Fotheringham AS. Analyzing numerical data. In: Flowerdew R, Martin $\mathrm{D}$, editors. Methods in human geography: a guide for students doing a research project. New York: Prentice Hall; 1997. p. 155-71.

13. Fotheringham AS, Brunsdon C, Charlton M. Quantitative geography perspectives on spatial data analysis. London: SAGE Publications; 2000.

14. Spurná P. Recent trends in quantitative analysis of geographic data focused on use of method of geographically weighted regression [thesis]. Prague: Charles University in Prague, Department of Social Geography and Regional Development,; 2006. (In Czech.)

15. Hendl J. Review of statistical methods for data processing - analysis and metaanalysis of data. Prague: Portál; 2004. (In Czech.)

16. Holt-Jensen A. Geography - history and concepts. London: SAGE Publications; 1999.

17. European Agency for Safety and Health at Work. European Occupational Diseases Statistics - EODS [Internet]. European Agency for Safety and Health at Work; 2014 [updated 2014 Apr 24; cited 2014 Jan 24]. Available from: http://hw2012.healthy-workplaces.eu/data/links/osh link.2005-0203.2544762875

Received August 8, 2014 Accepted in revised form September 22, 2014 